Pobrane z czasopisma Annales I - Philosophy and Sociology http://philosophia.annales.umcs.pl Data: 26/04/2023 01:29:04

DOI: $10.17951 /$ i.2017.42.2.43

A N N A LES

UNIVERSITATIS MARIAE CURIE-SKŁODOWSKA

LUBLIN - POLONIA

VOL. XLII, 2

SECTIO I

2017

GERARDO LÓPEZ SASTRE

Universidad de Castilla-La Mancha

\title{
¿Qué hay de sugerente y de actual en el pensamiento de Bartolomé de las Casas?*
}

Co jest sugestywne i aktualne w myśli Bartolomé de las Casasa?

Seguramente Bartolomé de las Casas (1484-1566) se veía a sí mismo como lo que hoy en día llamaríamos un activista o reformador social y político, pero lo cierto (y lo interesante para nosotros en este momento) es que en el desarrollo de su actividad presentó un conjunto de argumentos filosóficos muy bien articulados y que resultan sorprendentemente modernos, y este ensayo quisiera llamar la atención sobre los mismos y sobre su capacidad para iluminar algunos de los debates de nuestro mundo actual. Por poner un ejemplo, en el verano de este año que termina cuando escribo estas líneas, 2016, hemos asistido a una encendida polémica en Europa sobre el derecho de prohibiro no un determinado traje de baño en nuestras playas y piscinas, el ya famoso burkini. Evidentemente la discusión de fondo no es sobre la prenda en sí, sino sobre lo que parece representar. ¿Acaso no es un signo de sumisión de la mujer? ¿No es una forma de propaganda de una ideología fundamentalista? Pero cabría razonar que incluso si contestáramos afirmativamente a estas preguntas, todavía seguiría viva la cuestión de si debiera prohibirse o, por el contrario, tolerarse, confiando en este último caso en que a medio o largo plazo las mujeres que lo llevan acaben liberándose de tal prenda por decisión propia.

* Muchos de los argumentos que aquí desarrollo, aunque con un énfasis diferente y vinculados a otro tema, los presenté por primera vez en inglés hace años en el ensayo titulado National Prejudice and Religion in the Toleration Debate between Bartolomé de Las Casas and Juan Ginés de Sepúlveda, publicado en Religious Toleration: "The Variety of Rites" from Cyrus to Defoe, ed. J.C. Laursen, New York 1999, pp. 75-92. 
A lo mejor alejándonos un poco en el tiempo obtenemos una buena perspectiva para tratar este $\mathrm{u}$ otros problemas similares. Pensemos que el descubrimiento de América (descubrimiento, obviamente, para los europeos) supuso un choque cultural como seguramente no ha habido otro en la Historia; por lo inesperado, por su magnitud, etc. ${ }^{1}$ Un acontecimiento de este calibre puso en cuestión muchas ideas recibidas y generó múltiples preguntas sobre la identidad humana y la forma de relacionarnos con personas de otras culturas. En una situación así es probable que se responda con innovaciones conceptuales. Intentaremos probar que este fue el caso de Bartolomé de las Casas. A él le debemos una defensa extraordinariamente amplia de la tolerancia y algo bastante parecido a nuestra concepción de los derechos humanos. Y es importante insistir desde ya en la actualidad de algunos de sus planteamientos porque hay que reconocer que otros no llamarán mucho la atención al lector de nuestra época, sea secular o religioso ${ }^{2}$. Así, Bartolomé de las Casas observa que el asesinato de infieles -una práctica común de los conquistadores según nuestro autor- sin ofrecimiento previo de la verdadera fe y de los sacramentos, es algo especialmente grave y horrible en tanto que priva a esas víctimas de la salvación eterna. Para él, que esas personas asesinadas sufran ahora las torturas del fuego eterno añadía un peso importantísimo a la maldad de los españoles. Puede que este argumento moviera la conciencia de muchos de los lectores de su momento histórico. En el nuestro seguramente muy poco. Por una parte la cultura se ha secularizado, lo que ha sacado a la religión del ámbito de la discusión racional ${ }^{3}$. Es obvio que hablar de condenas eternas no es un argumento

1 Véase a este respecto J.H. Elliott, El viejo mundo y el nuevo (1492-1650), traducción de R. Sánchez Mantero, Madrid 1972, especialmente "1. El impacto incierto" y "2. El proceso de asimilación".

2 Marcel Bataillon y André Saint-Lu (El padre Las Casas y la defensa de los indios, traducción de J. Alfaya, B. McShane, Sarpe, Madrid 1985, p. 60) hacen muy bien en escribir: "No vamos a decir que Las Casas, pretendidamente antimoderno hacia 1560, se ha convertido en una figura de vanguardia cuando los imperialismos agotados pasan por la crisis de la descolonización. El único verdadero movimiento de la historia, es el de los hombres que viven en su tiempo con una mentalidad que es la de su tiempo; Las Casas no es un hombre sensible del siglo XVIII ni un humanitario del siglo XIX ni un descolonizador del XX. Es un cristiano del siglo XVI que creía en el evangelio y su propagación, que creía en el infierno y en el fin del mundo: semejante en esto a la mayor parte de sus compatriotas, comprendidos los más obsesionados por los tesoros del Nuevo Mundo". Pero para nosotros lo importante ahora mismo no es esto. No se trata de que no debamos contextualizar su pensamiento, sino de ver si con él surgen unos razonamientos que todavía podemos aprovechar porque nos parecen válidos.

3 Dicho de otra forma, hoy en día se ve la religión más como una experiencia que se predica que como un tema sobre el que se razona. El creyente busca más convertir que convencer. Hablará de los efectos vivificantes de la experiencia religiosa en su vida, de cómo siente que esta brilla más o es más plena, e intentará que los demás participen o lleguen a dotarse de una experiencia similar; pero -no nos engañemos- diálogo como intercambio de razones no habrá. A diferencia de 
para el que puedan ofrecerse razones. Por otra parte, el cristianismo ha evolucionado, algo que un pensador como William James analizó muy bien. Destacaba que cuando "cesamos de admirar o aprobar lo que implica la definición de una deidad terminamos por considerar a esa deidad como increíble"4. Y es así que a comienzos del siglo XX mantenía que la noción de una condena eterna había llegado a ser detestable, y por lo tanto increíble para los propios cristianos ${ }^{5}$.

Hecha la advertencia anterior, que no nos interesa todo lo que las Casas mantuvo, sino lo que nos parezca que pasa la criba del tiempo, podemos proceder ya. Como hilo conductor o argumental de nuestra exposición de las ideas de Bartolomé de las Casas vamos a utilizar algunos elementos de su debate con Juan Ginés de Sepúlveda en la junta de Valladolid, aunque -más allá de proporcionarnos una cierta estructura- no nos limitaremos a la misma. La junta tenía como objetivo considerar "el modo en que las conquistas se hagan con las justificaciones y medios que convengan, de manera que nuestro súbditos y vasallos las puedan hacer con buen título y nuestra conciencia quede descargada". Se ha podido escribir que "con sus fallas y sus timideces, la junta de Valladolid marca un hito: es la primera y quizás única vez en los anales de la historia que el conquistador se ha planteado de manera voluntaria y consciente la legitimidad de sus actos, analizada con todo rigor y frialdad en una reunión convocada expresamente con ese objeto"7. Eso

lo que pudo pensar la escolástica y una parte importante de la filosofía moderna, hemos llegado al convencimiento de que la religión pertenece al ámbito de la fe, no de la razón.

4 W. James, The Varieties of Religious Experience, Harmondsworth 1982, p. 329.

Ibídem.

6 Tomo la cita de esta célula real de B. Hernández, Bartolomé de las Casas, Barcelona 2015, p. 183.

J. Gil, Conquista y justicia: España y las Indias, [en:] Historia de la teoría política, ed. F. Vallespín, T. II, Madrid 1990, p. 421; y véase igualmente la opinión de Ángel Losada en su Introducción a Juan Ginés de Sepúlveda, Fray B. de Las Casas, Apología, traducción castellana de los textos originales latinos, introducción, notas e índices por Á. Losada, Madrid 1975, p. 12: "Bien podemos afirmar que por vez primera en la historia de la humanidad, una nación (España) y su Rey pusieron a discusión la justificación jurídica de una guerra que ambos estaban llevando a cabo, y que ello no fue mera palabrería sino que sus resultados fueron la promoción de toda una legislación posterior: la Legislación de Indias (ya iniciada antes de la junta) que con razón es considerada como base del moderno Derecho Internacional". Por supuesto, siempre podemos preguntarnos si habría algún motivo interesado detrás de esta postura aparentemente tan dispuesta a someter a examen y a crítica la actuación propia; por ejemplo, el miedo de la monarquía al desarrollo de un nuevo feudalismo, esta vez colonial. Lo cierto, e independientemente del contexto concreto de esta actuación, es que la cultura europea (en este caso, la española) parece presentar a lo largo de su historia moderna una notable capacidad para el escepticismo, para dudar de sí misma, para debatir sus presupuestos y para plantearse la bondad o maldad de sus acciones. Este es un elemento dinámico de la identidad europea cuya génesis más lejana quizá haya que buscar en su doble origen: Atenas y Jerusalén, elementos tan dispares que, a pesar de los intentos de síntesis, no pueden dejar de generar tensiones". 
Pobrane z czasopisma Annales I - Philosophy and Sociology http://philosophia.annales.umcs.pl Data: 26/04/2023 01:29:04

sí, también debemos subrayar que las Casas y Sepúlveda no coincidieron personalmente en las sesiones de la Junta, aunque gracias a sus escritos (y al sumario que preparó el dominico Domingo de Soto) sí que contamos con sus argumentos.

Comencemos exponiendo cómo Domingo de Soto resume la postura de Juan Ginés de Sepúlveda en relación a "si es lícito a Su Majestad hacer guerra a aquellos indios antes que se les predique la fe, para subjectallos a su Imperio, y que después de subjectados puedan más fácil y cómodamente ser enseñados y alumbrados por la doctrina evangélica del conocimiento de sus errores y de la verdad cristiana". Sepúlveda habría presentado cuatro argumentos que defenderían la legitimidad del recurso a la violencia:

1. Por la gravedad de los delitos de los indios, señaladamente por la idolatría $\mathrm{y}$ otros pecados que cometen contra natura.

2. Por la rudeza de sus ingenios. Es decir, los indios serían en virtud de su naturaleza gente servil y bárbara, "y por ende obligada a servir a los de ingenio más elegantes, como son los españoles".

3. Por el fin de la fe, "porque aquella sujeción es más cómoda y expediente para su predicación y persuasión".

4. "Por la injuria que unos entre sí hacen otros, matando hombres para sacrificarlos y algunos para comerlos".

Estudiemos con un mínimo de detalle la esencia lógica de estos argumentos. El primero no es tan sorprendente como a primera vista pudiera parecer. Más de una religión ha pensado que el verdadero creyente no puede tolerar lo que ofende al dios en el que cree, y que ese dios se molestaría bastante, hasta el grado de castigar a sus devotos, si estos no actuaran para impedir por la fuerza lo que saben que agravia a la deidad. Diríamos que de ahí la propensión de las confesiones religiosas a convertir lo que consideran pecados (un concepto teológico) en delitos (un concepto del derecho penal), imponiendo así su moralidad y sus prácticas al conjunto de la sociedad en la que viven o a otras diferentes.

En cuanto al segundo argumento de Sepúlveda, se ha empleado hasta la saciedad para justificar el colonialismo. Su historia es bien larga. Lo encontramos en Aristóteles y podemos verlo en la pesada carga del hombre blanco de la que nos hablara Rudyard Kipling. Desde luego, los españoles no se privaron de utilizarlo en el contexto de la conquista de América:

Debemos decir -declaró un experto anónimo, cuya opinión fue manifestada a Felipe III por el procurador general de los mineros de Nueva España en 1600- que los indios son siervos de los

8 B. de Las Casas, Controversia Las Casas-Sepúlveda, [en:] Obra indigenista, introducción y edición de J. Alcina Franch, Madrid 1995, p. 170.

9 Véase íbídem. 
españoles [...] por la doctrina de Aristóteles, lib. 1, Política, que dice que los que han menester ser regidos y gobernados por otros pueden ser llamados siervos de aquéllos [...] Y por esto la naturaleza hizo proporcionados los cuerpos de los indios, con fuerzas bastantes para el trabajo del servicio personal; y de los españoles, por el contrario, delicados y derechos y hábiles para tratar la policía y urbanidad $[\ldots]^{10}$.

Uno de los franciscanos que había pasado a las Indias en 1500, Francisco Ruiz, aseguraba que los naturales -es decir, los indios- "han menester, así como un caballo o bestia, ser regidos o gobernados por cristianos" $"$. Y en cuanto a Sepúlveda, este escribió:

Los que sobresalen en prudencia y talento, aunque no en robustez física, éstos son señores por naturaleza; en cambio, los tardos y torpes de entendimiento, aunque vigorosos físicamente para cumplir los deberes necesarios, son siervos por naturaleza, y añaden los filósofos que para éstos no sólo es justo, sino también útil, que sirvan a los que son por naturaleza señores. Y vemos que esto está sancionado también por ley divina en el libro de los Proverbios: 'El que es necio servirá al sabio'. Es creencia que tales son los pueblos bárbaros e inhumanos apartados de la vida civil, conducta morigerada y práctica de la virtud. A estos les es más beneficioso y más conforme al derecho natural el que estén sometidos al gobierno de naciones o príncipes más humanos y virtuosos, para que con el ejemplo de su virtud y prudencia y cumplimiento de sus leyes abandonen la barbarie y abracen una vida más humana, [...]. Y si rechazan su gobierno, pueden ser obligados por las armas, y esta guerra los filósofos enseñan que es justa por naturaleza con estas palabras: 'De esto resulta que en cierto modo brota de la naturaleza la obtención de riquezas por medio de la guerra, puesto que una parte de ella es la facultad de la caza, de la cual conviene usar no sólo contra las bestias, sino también contra aquellos hombres que habiendo nacido para obedecer rehúsan el dominio, pues tal guerra es justa por naturaleza' ${ }^{12}$.

¿Puede aplicarse esta teoría general al caso de los españoles y los indios? La respuesta de Sepúlveda es que sí:

10 Citado por J.H. Elliot, op. cit., p. 59. Francisco Fernández Buey escribe, y creo que es muy iluminador para entender la teoría de Aristóteles y su aplicación al caso de los indios: "En la teoría aristotélica de la esclavitud natural, varias veces recuperada a lo largo de la historia, [...], se defiende una subordinación natural de las pasiones al intelecto, tal que el esclavo es un hombre que no logra elevarse por encima de sus pasiones, dominar las pasiones. Aristóteles concede a este hombre la capacidad de razonar, al menos parcialmente, pero no de decidir en el sentido de autodeterminarse. El esclavo natural no es capaz de frónesis (sabiduría). Y como ésta es la facultad especulativa suprema que permite alcanzar la virtud, el esclavo sólo puede llegar a ella a través de otro, que es, precisamente, su amo". FF. Buey, La barbarie de ellos y de los nuestros, Barcelona-Buenos Aires-México 1995, p. 275. Esto implica que el esclavo es como un niño, así que por su propio bien ha de ser controlado por el adulto, por aquél que posee razón. De ahí la responsabilidad (la pesada carga, en palabras de Kipling) de este último.

11 Citado en J. Gil, op. cit., pp. 400-401.

12 J. Ginés de Sepúlveda, Demócrates segundo, edición crítica y traducción de A. Coroleu Lletget, [en:] Obras completas III, Excmo Ayuntamiento de Pozoblanco, 1997, pp. 55-56. La cita final que realiza Sepúlveda es de la Política de Aristóteles. La referencia de Proverbios es 11:29. 
[...] con perfecto derecho los españoles ejercen su dominio sobre esos indios del Nuevo Mundo e islas adyacentes, los cuales en prudencia, ingenio y todo género de virtudes y humanos sentimientos son tan inferiores a los españoles como los niños a los adultos, las mujeres a los varones, los crueles e inhumanos a los extremadamente mansos, los exageradamente intemperantes a los continentes y moderados ${ }^{13}$.

¿Qué pruebas pueden aducirse que acrediten la necedad de los indios? Para Sepúlveda carecen de cultura, no usan o conocen las letras, lo que conduce a que no tengan leyes escritas. Se pregunta, "¿qué se va a esperar de hombres entregados a toda clase de pasiones [...] y no poco dados a alimentarse de carne humana?". Por lo demás, es falso que vivieran en una situación idílica de paz. Al contrario, "se hacían la guerra continuamente entre sí con tanta rabia que consideraban nula la victoria si no saciaban su hambre prodigiosa con las carnes de sus enemigos". Alguien podría intentar contraargumentar aduciendo su arte, el hecho de que tuvieran casas, "algún modo racional de vida en común y el comercio a que induce la necesidad natural". Pero Sepúlveda no quiere que nos dejemos impresionar por estos logros. ¿Acaso no vemos cómo ciertos animalitos, como las abejas y las arañas, hacen obras que la habilidad humana no puede imitar? Y en cuanto a su vida social y comercial, "¿qué prueba sino que ellos no son osos o monos carentes por completo de razón?"'14. Tomando en cuenta todo esto, se comprende lo tajante de la conclusión de Sepúlveda:

[...] ¿dudaremos en afirmar que estas gentes tan incultas, tan bárbaras, contaminadas con tan nefandos sacrificios e impías religiones, han sido conquistadas por rey tan excelente, piadoso y justo como fue Fernando y lo es ahora el César Carlos, y por una nación excelente en todo género de virtudes con el mejor derecho y mayor beneficio para los indios? Antes de la llegada de los cristianos tenían la naturaleza, costumbres, religión y práctica de nefandos sacrificios que hemos explicado; ahora, al recibir con nuestro gobierno nuestras letras, leyes y moral, imbuidos de la religión cristiana, quienes se han mostrado dóciles a los sacerdotes que les hemos mandado, como muchos lo han hecho, tanto se diferencian de su primitiva condición como los civilizados de los bárbaros, los

13 J. Ginés de Sepúlveda, Demócrates segundo, p. 64. Conviene subrayar que si los crueles son inferiores a los "extremadamente mansos", una vez que se aceptara como cuestión de hecho la descripción que Las Casas hace de las crueldades de los españoles y de la mansedumbre de los indios -leyendo por ejemplo su Brevísima relación de la destrucción de las Indias- podríamos convencernos de que los conquistadores son los verdaderos bárbaros. La Brevisima se convirtió en la obra más famosa de Bartolomé de Las Casas, traduciéndose rápidamente a otros idiomas europeos, aunque seguramente esto tuvo más que ver con el hecho de que podía utilizarse como arma de guerra, contribuyendo así a la formación de la leyenda negra, que a su rigor histórico. En todo caso, y como vamos a mencionar en un momento, Sepúlveda no acepta la tesis de la mansedumbre de los indios, sino que subraya su carácter belicoso. Otra cosa es que al mismo tiempo, dirá este autor, los indios carecieran de fortaleza de ánimo y fueran propensos a la cobardía. Veáse íbidem, pp. 66-67.

${ }_{14}$ Véase íbídem, pp. 65-67. 
provistos de vista de los ciegos, los inhumanos de los mansos, los piadosos de los impíos, en una palabra y para decirlo de una vez, casi cuanto los hombres de las bestias ${ }^{15}$.

El resultado de la argumentación estaba claro: los españoles habían civilizado a los indios que aceptaron su dominio. Estos, gracias a los conquistadores, habían pasado de la ceguera a la luz. Desde luego, esta era una justificación poderosa.

Pasando al tercer argumento, este tiene que ver con la idea de que el uso de la fuerza, el control del poder temporal, podría suprimir los impedimentos que se presenten a la predicación de la religión verdadera, el cristianismo. Diríamos que es más fácil que los indios escuchen la predicación cristiana si previamente están sometidos al poder de los españoles. Por supuesto, esto no garantiza la conversión, que es algo que surge de la voluntad, pero sí es verdad que así es más probable que ocurra. Diríamos que se ha allanado el camino.

El cuarto argumento que justifica el uso de la violencia es lo que hoy llamamos "intervención humanitaria". Los indios mataban a numerosos inocentes en sus sacrificios o para comérselos. Según Ginés de Sepúlveda, en la Nueva España se sacrificaban cada año más de veinte mil personas. Si multiplicamos ese número por treinta años, que son los que han pasado desde que los españoles impidieron esas prácticas, tendríamos que la acción humanitaria de estos ha evitado seiscientas mil muertes ${ }^{16}$. ¿No justifica la salvación de tantas víctimas el uso de la violencia?

Después de esta sucinta exposición de los argumentos de Sepúlveda ha llegado ya el momento de pasar a las réplicas de las Casas. Como respuesta al primer argumento de Sepúlveda, las Casas propone el reconocimiento de la separación entre el orden civil y el religioso. Las Casas observa que por razón de domicilio los judíos y moros que viven en los reinos de los príncipes cristianos son súbditos de los mismos:

[...] tales judíos y moros están obligados a someterse a las mismas leyes temporales que los demás habitantes del reino, y si quebrantan dichas leyes, por ellas son castigados, [...]. Ahora bien, en lo que se refiere a la religión y asuntos espirituales, ya se trate de judíos, ya de mahometanos o de idólatras, de ninguna manera tales personas están sometidas a la Iglesia o a sus miembros, a saber, los príncipes cristianos; por tanto, por el hecho de celebrar y observar sus ritos, de ninguna manera pueden ser castigadas por los príncipes cristianos, pues éstos carecen de esta parte de jurisdicción, ya que los crímenes de aquellos por muy graves y abominables que sean, sin embargo no pueden ser castigados por los hombres, [...] /Tratemos ahora de los infieles que habitan los reinos sometidos a los príncipes infieles, como son los moros, los turcos, [...] y estos de quienes se discute, a saber, los indios. Es indudable que, por muy horrendos que sean los crímenes que cometan, entre sí y dentro de su territorio, contra Dios o en materia religiosa, ni la Iglesia ni los príncipes cristianos tienen poder para juzgarlos ni para castigarlos por causa de tales crímenes, pues carecen

$15 \quad$ Ibidem, p. 68.

16 Véase para estas cifras B. Las Casas, Controversia Las Casas-Sepúlveda, p. 210. 
de jurisdicción [...]/ Ahora bien, caso distinto es el de los herejes, pues éstos están sometidos a los príncipes cristianos no solamente por razón de domicilio, de origen, de contrato y de delito, sino también por razón de voto y obediencia prometida, voto que hicieron y obediencia que prometieron en el bautismo a Dios y a la Iglesia Católica; todo lo cual si no cumplen con pleno derecho son castigados por los príncipes y por las leyes, tanto pontificias como imperiales ${ }^{17}$.

La última parte de esta cita nos indica una cierta limitación (al menos vista desde hoy en día) del planteamiento de las Casas. No parece admitir que las personas tengan el derecho de replantearse la que para él es la religión verdadera. Como si la decisión de entrar en la vida cristiana no pudiera tener vuelta atrás, fuera una decisión irrevocable; pero quitando esta situación, su réplica a Sepúlveda es el establecimiento de una clara separación entre la jurisdicción civil, que todos deben acatar, y la jurisdicción religiosa. Y en este ámbito, ya Dios juzgará a los que están fuera. Luego castigar a los indios por sus idolatrías queda fuera de la jurisdicción de los españoles. Este no es un título legítimo que justifique su presencia armada en América.

Con respecto al segundo punto, Bartolomé de las Casas nos presenta una descripción de la vida india y de su carácter que no podría ser más opuesta a la de Sepúlveda:

[...] no son necios ni crueles ni fieros, sino que mucho antes de que conociesen el nombre de España tenían repúblicas rectamente instituidas, a saber, sobriamente administradas por una óptima legislación, religión e instituciones, cultivaban la amistad y, unidos en sociedad de vida habitaban muy grandes ciudades en las que prudentemente con bondad y entidad administraban los negocios tanto de la paz como de la guerra; así su gobierno se regía por una legislación que en muchas cosas supera a la nuestra y que podría causar la admiración de los sabios de Atenas ${ }^{18}$.

También podemos citar este otro texto en donde se mantiene que las gentes de las Indias:

[...] tenían sus repúblicas, lugares, villas y ciudades suficientísimamente proveídas y abundantes, sin que para vivir política y socialmente y alcanzar y gozar de la felicidad civil, que en esta vida cualquiera buena y razonable y proveída y felice república tener y gozar desea, les faltase nada, unas más y otras poco menos y munchas en gran perfección, todo por la mayor parte, porque son todas naturalmente de muy sotiles, vivos y claros y capacísimos entendimientos. Esto les provino (después de la voluntad de Dios, que quiso así hacerlas) por la favorable influencia de los cielos, por la disposición suave de las regiones que Dios les concedió que habitasen, [...] por la compostura de los miembros y órganos de los sentidos exteriores e interiores [...] y también a posteriori, que es decir por las mismas obras que obran y efectos que hacen. De todas estas causas universales y superiores, y particulares inferiores, naturales y accidentales, se les siguió por vía natural primero, y después

17 Idem, Apología, pp. 145-146.

18 Ibidem, pp. 134-135. 
Pobrane z czasopisma Annales I - Philosophy and Sociology http://philosophia.annales.umcs.pl Data: 26/04/2023 01:29:04

¿Qué hay de sugerente y de actual en el pensamiento de Bartolomé de las Casas?

por su industria y experiencia, ser dotadas de las tres especies que hay de prudencia, monástica, por la cual el hombre sabe regir a sí mismo; económica, que sabe regir a su casa, y política, que ordena y dispone para regir la ciudad ${ }^{19}$.

Está claro que si ya disponen de prudencia personal y política no necesitan que los españoles les controlen como si fueran niños ni les impongan ningún tipo de gobierno. Ellos pueden perfectamente gobernarse a sí mismos.

Hasta aquí la réplica de las Casas se ha movido en el terreno de la apelación a los hechos. Si Sepúlveda decía que los indios carecían de prudencia, que eran como niños necesitados de adultos que los protegieran de sí mismos y los educaran, nuestro autor aducirá que sus capacidades les habían permitido elaborar leyes que despertarían la admiración de los sabios griegos. Si uno hablaba de su crueldad, el otro insistía en su carácter pacífico. Y llegados a este punto, la verdad es que uno no puede dejar de preguntarse si las Casas está haciendo una descripción adecuada de cómo eran las sociedades indias, o si no las estará idealizando. En suma, ¿conoce de verdad a los indios? Haciendo la misma pregunta con un sesgo ligeramente distinto ¿nos ayuda su obra a conocerlos? Creo que la respuesta tiene que ser negativa. La imagen que ofrece nuestro autor de la conquista de América es la del enfrentamiento sin paliativos entre el bien y el mal en un esquema simplista. Este es un punto que Tzvetan Todorov ha sabido ver muy bien: la originalidad de la posición de las Casas estaría en colocar a los indios como representantes del bien y a los españoles como malvados. Esto último es verdad hasta tal punto que las Casasequipara a los conquistadores con diablos: "Considérese [...] si les cuadra bien a los tales cristianos llamallos diablos, e si sería más encomendar los indios a los diablos del infierno que es encomendarlos a los cristianos de las Indias". O piénsese en las páginas iniciales de la Brevísima, en donde se habla de los indios como ovejas mansas entre las que entraron los españoles como "lobos e tigres y leones cruelísimos de muchos días hambrientos". A este respecto Todorov constata que: "Las Casas conoce a los indios menos bien que Cortés, y los quiere más; [...]. El conocimiento no implica el amor, ni a la inversa"20. El resultado es que, en lo que se refiere a nuestro tema, para tolerar al otro a lo mejor no necesito conocerlo y me viene muy bien idealizarlo. Evidentemente, no podemos seguir aquí todas las implicaciones de esta tesis que nos lleva a las complejas relaciones entre conocimiento e intereses. Puedo poner el conocimiento al servicio del dominio (lo que sin duda hacía Cortés) o puedo decidir idealizar a los indios, alejándome

19 Idem, Apologética Historia Sumaria, capítulo 268, [en:] Obras completas, T. VIII, Madrid 1992, capítulo 263, p. 1571.

20 Véase T. Todorov, La conquista de América. El problema del otro, traducción de F. Botton Burlá, México 1987, p. 180 y 195. 
del conocimiento, para así defender sus intereses. Esta perspectiva puede tener su mérito y puede que quepa defenderla en casos concretos, pero a largo plazo seguramente está condenada al fracaso. Parece evidente que la ética y el conocimiento deben ir de la mano. No cada uno por su lado.

Como si supiera que su argumentación puede cuestionarse, en un determinado momento las Casas va a adoptar otra estrategia. Una estrategia que ya no dependerá del recurso a los hechos. Diríamos en terminología filosófica que ya no vamos a estar en presencia de un argumento a posteriori (aportando pruebas) sino a priori. Se tratará de la postulación de un principio que tiene una función metodológica. Entra así en escena lo que consideramos que es un precedente de nuestra actual creencia en los derechos humanos ${ }^{21}$. En efecto, las Casas va a proceder a defender la igualdad en dignidad de todos los hombres:

La razón desta verdad es, y pónelaTullio en el libro $1^{\circ}$ De legibus, conviene a saber, porque todas las naciones del mundo son hombres, y de todos los hombres y de cada uno dellos es una no más la definición, y ésta es que son racionales; todos tienen su entendimiento y su voluntad y su libre albedrío como sean formados a la imagen y semejanza de Dios; [...] todos tienen los principios naturales o simientes para entender y para aprender y saber las sciencias y cosas que no saben, [...]. Así que todo linaje de los hombres es uno ${ }^{22}$.

Por supuesto, este linaje común no impide reconocer que algunos no se han desarrollado y necesiten para ello de la ayuda de otros, que a su vez fueron en su momento enseñados y guiados; pero ahora lo importante es otra cosa, el reconocimiento de que "Todas las naciones del mundo tienen entendimiento y voluntad"23; y si partimos del convencimiento de que todos los seres humanos somos racionales, habremos de concluir que a una criatura racional no se la subordina a otra. Esto, decíamos es una presupuesto metodológico. Supone admitir que el otro es igual que yo, y que cuando hace algo extraño o que me sorprende, no es que no tenga

21 Para este tema puede verse el conjunto de estudios de Mauricio Beuchot reunidos en su libro Los fundamentos de los derechos humanos en Bartolomé de las Casas, prólogo de S. Zavala, Barcelona 1994. Del mismo autor hay una introducción al pensamiento de Las Casas tan breve como excelente: Bartolomé de las Casas (1484-1566), Madrid 1995.

22 B. de Las Casas, Apologética Historia Sumaria, capítulo 48, [en:] Obras completas, T. VII, Madrid 1992, pp. 536-537. Y en otro lugar escribe: "De esta forma Tulio en De Legibus dice: Cualquiera que sea la definición de hombre, ésa vale para todos. Lo cual es argumento suficiente de que ninguna desemejanza hay en la naturaleza; si existiera alguna, no comprendería a todos los hombres una misma definición./ En efecto, la razón, que es lo único que nos hace superiores a los animales, por la cual somos capaces de conjeturar, argumentamos, refutamos, disertamos, demostramos algo, y sacamos conclusiones, es ciertamente común. Diferente en la cultura, pero par en la facultad de aprender". Idem, De unicovocationis modo, [en:] Obras completas, T. II, Madrid 1992, p. 373.

$23 \quad$ Idem, Apologética..., p. 537. 
cultura, es que tiene una distinta que debo intentar entender. Los presupuestos de la antropología moderna están aquí sentados. Con esto el aristotelismo desaparece para ser sustituido por un igualitarismo de raíces estoicas y cristianas. Diríamos que como categoría general ya no hay siervos por naturaleza. Podrá haber lo que las Casas llama algún "mentecato" (uno entre cien mil, dice) que deba ser "ser puesto debajo de ley e orden", pero es "imposible de toda imposibilidad que una nación toda sea inhábil o tan poco y barbarísimo juicio y de baja y apocada razón que no se sepa gobernar y que no pueda ser inducida y atraída y doctrinada en cualquiera buena doctrina moral" 24 .

Si ese es un presupuesto que los españoles en tanto que cristianos debieran asumir, ¿por qué tantos están convencidos del carácter bárbaro de los indios? ¿No será porque necesitan esa justificación para establecer su dominio y poder explotarlos mejor? Haciéndonos la misma pregunta en una terminología moderna, ¿no estaremos en presencia de una ideología en el sentido marxista de esta palabra? Bartolomé de las Casas es muy consciente (y quiere que nosotros también tomemos conciencia) de que el fin último de los cristianos -de los llamados "cristianos" habría que decir- ha sido el oro, su verdadera dios:

La causa porque han muerto y destruido tantas y tales y tan infinito número de ánimas los cristianos ha sido solamente por tener por su fin último el oro y henchirse de riquezas en muy breves días y subir a estados muy altos e sin proporción de sus personas, conviene a saber, por la insaciable cudicia y ambición que han tenido, que ha sido la mayor que en el mundo ser pudo, por ser aquellas tierras tan felices y tan ricas, e las gentes tan humildes, tan pacientes y tan fáciles a sujectarlas; a las cuales no han tenido más respecto ni dellas han hecho más cuenta ni estima (hablo con verdad, por lo que sé y he visto todo el dicho tiempo) no digo que de bestias (porque pluguiera a Dios que como a bestias las hubieran tratado y estimado) pero como y menos que estiércol de las plazas ${ }^{25}$.

\section{O como dirá en otro momento:}

Los hombres mundanos y ávidos buscan nadar en riquezas y placeres en este mundo [...]. Del modo más expedito y sin ningún impedimento, intentan conseguir, el oro y la plata en los que habían puesto su esperanza, extrayéndolos de los sudores y trabajos, más aún, de la durísima opresión y de la muerte con grandes estragos, tormentos y otras injurias y gravámenes de innumerables hombres, más aún, de la mayor parte del género humano. Han discurrido un nuevo modo de colorear algún tanto sus injusticias y tiranías, y de justificarse en su juicio. Tal ha sido atribuir con falsedad a las naciones indianas, que tanto se apartaban del régimen común de los hombres, que no eran capaces de gobernarse a sí mismos, sino que necesitaban de tutores. Y ha llegado a tanto el delirio y reprobable descaro de éstos, que no han dudado en afirmar e infamar infantilmente que aquellos hombres eran bestias o cuasibestias, y por consiguiente, con razón, como a bestias

24 Ibídem.

25 Idem, Brevísima relación de la destrucción de las Indias, [en:] Obra indigenista, p. 71; y véase F.F. Buey, La gran perturbación. Discurso del indio metropolitano, Barcelona 1995, pp. $321-322$. 
los podían someter a su dominio con la guerra, o cazarlos, y después reducirlos a esclavitud y, por tanto utilizarlos a su capricho ${ }^{26}$.

Por el contrario, las Casas pretende que las grandes palabras que la ideología proclama, y que no son sino algo que se utiliza para "colorear" y disimular el verdadero objetivo, se tomen en serio, no como un mero subterfugio detrás del que se esconde el deseo de enriquecimiento. Lo cierto es que los españoles no han intentado realmente llevar el cristianismo a las tierras que han ido descubriendo ${ }^{27}$; pero si de verdad los españoles quisieran evangelizar a los indios, y las Casas piensa que si aspiran a ser buenos cristianos es lo que debieran hacer, ¿cómo debieran proceder?

La pregunta anterior puede formularse de otra manera más concreta: ¿cómo debe promoverse la fe? Este era el tema del tercer argumento de Sepúlveda, que justificaba para este fin el uso de la violencia. Por el contrario, las Casas va a partir de la teoría de Aristóteles del movimiento natural, lo que demuestra su capacidad para coger de cada pensador lo que más le interesa, desechando al mismo tiempo otras partes, para elaborar así una teoría propia. Las Casas observa que:

El modo normal de mover y dirigir las cosas naturales al bien de su propia naturaleza es que se muevan y se dirijan o sean atraídas según la modalidad y naturaleza de cada una, como enseña el Filósofo en el libro segundo de los Físicos: Cada cosa, por naturaleza -dicese mueve y se inclina conforme a la aptitud nativa para moverse e inclinarse. Así vemos que las cosas pesadas, por ejemplo la piedra, se mueven naturalmente de una manera y, de otra, las cosas ligeras, por ejemplo el fuego, por la naturaleza distinta de cada una. La creatura racional hanacido con aptitud para ser movida, conducida, dirigida y atraída blandamente, con dulzura, con delicadeza y suavemente, por su libre albedrío, de modo que voluntariamente escuche, voluntariamente obedezca, voluntariamente se adhiera y se someta. Luego, el modo de mover y dirigir, y de atraer a conducir a la criatura racional al bien, a la verdad, a la virtud, a la justicia, a la recta fe y a la verdadera religión debe ser conforme al modo, naturaleza y condición de la misma creatura racional es decir, dulce, blando, delicado y suave, de forma que espontáneamente, con voluntad de libre albedrío, con su índole natural y capacidad escuche las cosas que se le proponen ${ }^{28}$.

Hay que concluir, por lo tanto, que sólo cabe la predicación pacífica. Para cambiar las creencias de un ser racional hay que proponer razones: y si la exposición de las mismas no da el resultado apetecido, y los indios deciden mantenerse en su antigua religión -o incluso si deciden no escuchar la predicación cristiana- no podrá hacerse otra cosa salvo perseveraren el ejemplo y la argumentación y confiar en obtener mejores resultados en el futuro.

\footnotetext{
26 B. de Las Casas, De unicovocationis modo, p. 351.

27 Véase para esta afirmación en idem, Brevísima relación de la destrucción..., p. 146.

28 Idem, De unicovocationis modo, p. 25.
} 
Por lo demás, y esta sería la verdadera objeción a Sepúlveda, una predicación acompañada de violencia no podría nunca conseguir los resultados deseados, sino todo lo contrario. Los indios llegarían a aborrecer la Ley de Dios, pues la atribuirían los males, calamidades y tiranías que de la conquista se siguen. Pensarían que sus dioses eran mejores que el Dios cristiano, pues la aparición de este sólo les ha traído males. ¿No sería una reacción natural en este contexto que aborrecieran al cristianismo? Este ha sido el resultado de la violencia, pues como señala Las Casas los indios "quieren antes ser comidos de tigres que salirse donde puedan ser vistos y tratados de los cristianos" 29 . Los resultados del empleo de la violencia, y del encuentro de los indios con la catadura moral de los españoles que a las Indias acuden no pueden ser más paradójicos. En la Brevísima, Las Casas cuenta la anécdota de un cacique indio que va a ser quemado por haberse opuesto a las crueldades de los españoles.

Atado al palo decíales un religioso de Sant Francisco, [...], algunas cosas de Dios y de nuestra fe (el cual nunca las había jamás oído), lo que podía bastar aquel poquillo tiempo que los verdugos le daban, y que si quería creer aquello que le decía que iría al cielo, donde había gloria y eterno descanso, e si no, que había de ir al infierno a padecer perpetuos tormentos y penas. El, pensando un poco, preguntó al religioso si iban cristianos al cielo. El religioso le respondió que sí; pero que iban los que eran buenos. Dijo luego el cacique, sin más pensar, que no quería él ir allá, sino al infierno, por no estar donde estuviesen y no ver tan cruel gente ${ }^{30}$.

Y Las Casas concluye: "Esta es la fama y honra que Dios e nuestra fe ha ganado con los cristianos que han ido a las Indias" 31.

Si para evitar estos resultados como este nos convencemos de que la única predicación válida es la pacífica, ¿cómo podría desarrollarse de una forma realista? En algunos lugares, los predicadores podrían proceder directamente, en otros la prudencia aconsejaría que utilizaran a indios ya convertidos como intermediarios y que se preocuparan de su posible defensa:

Envíense, de las regiones ya aplacadas y en las que algunos ya han abrazado nuestra fe, legados de entre aquellos recientemente convertidos, para que actúen en nombre de algunos piadosos y religiosos varones, a los cuales ellos ya son adictos; envíense, digo, estos legados a anunciar a las demás gentes de su provincia cómo aquellos piadosos predicadores, totalmente alejados de las costumbres de los demás sicarios, van a aquellas provincias precisamente a anunciarles el camino de la verdad y el culto al verdadero Dios. De este modo yo he logrado atraer a la fe a extensísimas provincias. Después, sería útil levantar una ciudadela en un lugar apropiado, para residencia de los predicadores, defendida por una guardia de personas buenas y probadas, guardia no dispuesta

\footnotetext{
29 Véase para esta cita y para todo lo anterior M. Bataillon y A. Saint-Lu, op. cit., pp. 173-182.

30 B. de Las Casas, Brevísima relación de la destrucción..., p. 81.

31 Ibídem.
} 
en todo momento a matar y a robar a los indios y a la que nuestro Príncipe debería dotar de un magnífico salario ${ }^{32}$.

Entramos, por último, en la réplica de las Casas al cuarto argumento de Sepúlveda, el que parece tener más fuerza: la defensa de víctimas inocentes. A este respecto las Casas nos propone realizar un cálculo sobre el alcance de dos tipos de males: la tolerancia de esa conducta y la intervención armada, estando claro que se debiera adoptar el mal menor. ¿Y no es muy probable que el recurso a la guerra acabe ocasionado males mayores? Nuestra reacción inmediata ante una atrocidad como el sacrificio de seres humanos será la de intervenir para evitarlo, pero las Casas insiste en que se debe ponderar mucho la cuestión, no vaya a ser que para impedir la muerte de unos cuantos inocentes sacrifiquemos una multitud innumerable de hombres, sin que estos lo merezcan, destruyamos reinos enteros e inculquemos en las almas de aquéllos el odio a la religión cristiana de manera que para siempre se nieguen a oír el nombre de Cristo o su doctrina ${ }^{33}$. El resultado de esta argumentación es una tolerancia que podríamos llamar utilitarista: “[...] tal tolerancia es legítima cuando se permiten males y aun pecados graves para que se eviten otros más graves en la república o para que no se pongan obstáculos a los bienes por los cuales se hace más firme el estado de la república" ${ }^{34}$.

Pero es que, además, en las Casas hay un intento de comprender las razones que pueden encontrarse detrás de la realización de los sacrificios humanos. Al fin y al cabo, hemos visto que se postulaba la plena racionalidad de los indios, luego alguna explicación racional ha de haber de su conducta. Las Casas comienza notando que estamos ante una práctica que se encontraba en muchos pueblos: entre los galos, los escitas e incluso los propios romanos. Por no decir, que en el casodel cristianismo podemos pensar en la orden dada por Dios a Abraham de inmolar a su único hijo Isaac ${ }^{35}$. Por lo tanto, hemos de hacernos la siguiente pregunta ¿qué razones puede haber detrás de una práctica más extendida de lo que a primera vista podría pensarse? La contestación es que todos los pueblos tienen, aunque confuso, un cierto conocimiento de Dios, de "algo que está por encima y es mejor

32 Idem, Apología, p. 241. En una nota de la misma página Ángel Losada comenta que estos párrafos "nos brindan el mejor resumen del programa típicamente lascasiano de predicación pacífica (que, como vemos, no rehúsa del todo el auxilio de la fuerza armada, con fines, eso sí, exclusivamente defensivos)". Y véase: idem, Controversia Las Casas-Sepúlveda, pp. 195-196.

33 Véase idem, Controversia Las Casas-Sepúlveda, p. 192.

34 Idem, Apología, p. 253. Y a continuación las Casas remite como autoridad de esta propuestade que no debe hacerse la guerra a los indios por ese motivo al "doctísimo Maestro Francisco de Vitoria en su »Secunda Relectio de Indis«. De todas formas, hay que notar que Sepúlveda utiliza el mismo cálculo utilitario con el resultado opuesto".

35 Véase idem, Controversia Las Casas-Sepúlveda, pp. 193-194. 
Pobrane z czasopisma Annales I - Philosophy and Sociology http://philosophia.annales.umcs.pl Data: 26/04/2023 01:29:04

¿Qué hay de sugerente y de actual en el pensamiento de Bartolomé de las Casas?

que todas las cosas" ${ }^{36}$. Pues bien, ¿cómo pueden los hombres manifestar el amor o la devoción que tienen hacia ese ser divino del que creen que procede todo lo que poseen? Pues ofreciéndole lo que les es más querido, la vida:

[...] saben que el modo principal de reverenciar a Dios es ofrecerle sacrificios, acto éste el único por el que demostramos que aquél a quien los ofrecemos es Dios y nosotros sus súbditos agradecidos. Además, la naturaleza nos enseña que es justísimo que ofrezcamos a Dios, de quien por tantos motivos nos reconocemos deudores, por la admirable eminencia de su majestad, las cosas más preciosas y excelentes. Ahora bien, según la verdad y juicio humanos, ninguna cosa hay para los hombres más importante y preciosa que su vida ${ }^{37}$.

Tenemos, entonces, que los sacrificios humanos de los indios tienen a su base una argumentación. Esta podrá estar equivocada, no tomar en cuenta otras razones (pensemos, por ejemplo, que si Dios da la vida sólo él puede quitarla) o ser contraria a la fe revelada. Pero entonces, hay que exponerles los argumentos o enseñarles las doctrinas que debieran llevarles a cambiar de opinión. En suma, hay que razonar con ellos.

Si ahora entramos en el mundo actual y nos encontramos con prácticas mucho menos dramáticas, sea con adolescentes que aparecen con velo en las escuelas o con mujeres que llevan el burkini mencionado en las playas, honestamente no parece que haya ninguna buena razón para obligarlas por la fuerza (diríamos, con la ley en la mano) a despojarse de tales prendas. Bartolomé de las Casas hubiera pensado que muy poca confianza tenemos en el poder de la educación o en el atractivo de nuestro modo de vida cuando no esperamos que se contagie libremente y que entre sus efectos tengan el que en un determinado momento esas mujeres acaben quitándose voluntariamente lo que en su ignorancia creían que las protegía y ahora ven como un signo de sumisión. ¿O es que creemos que les falta la capacidad de razonar?

Y si pasamos ahora al terreno de las relaciones internacionales -que al fin y al cabo era la perspectiva desde la que escribía Bartolomé de las Casas- cabe argumentar algo parecido. El mundo está lleno de gobiernos no democráticos y de dictaduras opresivas, pero a la hora de invadir un país y derrocar por la fuerza a sus dirigentes parece razonable pensar en los costes humanos y en la situación que se va a dejar como herencia. Muchas veces, por intentar traer el paraíso a la tierra se ha construido un infierno. No se trata de que dejemos de confiar en los derechos humanos -nada podría estar más lejos de las enseñanzas de las Casas- sino

36 Idem, Apología, p. 280. Una de las autoridades a las que se recurre, una vez más, es Cicerón: "No hay gente tan indómita y fiera cuya mente no esté imbuida de la creencia en la divinidad". Ibídem.

37 Ibidem, p. 286. 
que pensamos que el fin no justifica determinados medios y que estos raramente producen el resultado prometido. A cualquier lector familiarizado con la historia del mundo árabe y las actuaciones occidentales en el mismo se le ocurrirá en qué podemos estar pensando. Confiar en el ejemplo y en la razón puede que a largo plazo sea más provechoso.

\section{BIBLIOGR AFÍA}

Bataillon M., Saint-Lu A., El padre Las Casas y la defensa de los indios, traducción de J. Alfaya, B. McShane, Madrid 1985.

Beuchot M., Bartolomé de las Casas (1484-1566), Madrid 1995.

Beuchot M., Los fundamentos de los derechos humanos en Bartolomé de las Casas, prólogo de S. Zavala, Barcelona 1994.

Buey F.F., La barbarie de ellos y de los nuestros, Barcelona-Buenos Aires-México 1995.

Buey F.F., La gran perturbación. Discurso del indio metropolitano, Barcelona 1995.

Elliott J.H., El viejo mundo y el nuevo (1492-1650), traducción de R. Sánchez Mantero, Madrid 1972.

Gil J., Conquista y justicia: España y las Indias, [en:] Historia de la teoría política, ed. F. Vallespín, T. II, Madrid 1990.

Ginés de Sepúlveda J., Demócrates segundo, edición crítica y traducción de A. Coroleu Lletget, [en:] Obras completas III, Excmo Ayuntamiento de Pozoblanco, 1997.

Hernández B., Bartolomé de las Casas, Barcelona 2015.

James W., The Varieties of Religious Experience, Harmondsworth 1982.

Las Casas B. de, Apologética Historia Sumaria, capítulo 48, [en:] Obras completas, T. VII, Madrid 1992.

Las Casas B. de, Apologética Historia Sumaria, capítulo 268, [en:] Obras completas, T. VIII, Madrid 1992,

Las Casas B. de, Apología, traducción castellana de los textos originales latinos, introducción, notas e índices por Á. Losada, Madrid 1975.

Las Casas B. de, Brevísima relación de la destrucción de las Indias, [en:] Obra indigenista, introducción y edición de J. Alcina Franch, Madrid 1995.

Las Casas B. de, De unicovocationis modo, [en:] Obras completas, T. II, Madrid 1992.

Las Casas B. de, Obra indigenista, introducción y edición de J. Alcina Franch, Madrid 1995.

Religious Toleration: "The Variety of Rites" from Cyrus to Defoe, ed. J.C. Laursen, New York 1999. Todorov T., La conquista de América. El problema del otro, traducción de F. Botton Burlá, México 1987.

\section{SUMMARY}

In this article we present the theory of religious tolerance of Bartolomé de las Casas, his criticism of the use of violence as an instrument of conversion, and the elements of his thinking that contribute to the elaboration of the ideal of human rights. In this way we try to demonstrate the present value of his ideas.

Keywords: Bartolomé de las Casas; toleration; human rights; just war 
Pobrane z czasopisma Annales I - Philosophy and Sociology http://philosophia.annales.umcs.pl Data: 26/04/2023 01:29:04

¿Qué hay de sugerente y de actual en el pensamiento de Bartolomé de las Casas?

\section{STRESZCZENIE}

W niniejszym artykule przedstawiamy teorię tolerancji religijnej Bartolomé de las Casasa, jego krytykę użycia przemocy jako narzędzia przekształcenia oraz elementy jego myślenia, które przyczyniają się do wypracowania ideału praw człowieka. W ten sposób staramy się pokazać aktualną wartość jego pomysłów.

Słowa kluczowe: Bartolomé de las Casas; tolerancja; prawa człowieka; tylko wojna

\section{RESUMEN}

En este artículo analizamos la teoría de la tolerancia religiosa de Bartolomé de las Casas, sus críticas al uso de la violencia como instrumento de conversión, y los elementos de su pensamiento que conducen a la elaboración del ideal de los derechos humanos. Con ello pretendemos demostrar la actualidad de sus planteamientos.

Palabras claves: Bartolomé de las Casas; tolerancia; derechos humanos; guerra justa 